\title{
Common fixed point and solution of nonlinear functional equations
}

Abdul Rahim Khan*

"Correspondence: arahim@kfupm.edu.sa

Department of Mathematics and Statistics, King Fahd University of Petroleum and Minerals, Dhahran, 31261, Saudi Arabia

\begin{abstract}
Convergence of a new iterative scheme, containing Mann and Ishikawa iterative schemes, for asymptotically nonexpansive mappings on a 2-uniformly convex hyperbolic space is studied. As application, we find a solution of a system of certain nonlinear functional equations in uniformly convex Banach spaces.
\end{abstract}

MSC: $47 \mathrm{H} 09 ; 47 \mathrm{H} 10$

Keywords: uniformly convex hyperbolic space; asymptotically nonexpansive mapping; common fixed point; convergence

\section{Introduction}

The Banach contraction principle asserts that a contraction on a complete metric space has a unique fixed point and its proof hinges on 'Picard iterations.' This principle is applicable to a variety of subjects such as integral equations, partial differential equations and engineering of image processing.

Many important nonlinear problems of mathematics reduce to nonlinear functional equations such as nonlinear integral equations and boundary value problems for nonlinear ordinary or partial differential equations which can be translated in terms of a fixed point equation $T x=x$ for a given nonlinear mapping $T$ on a Banach space or a metric space.

Browder and Petryshyn [1] solved the equation

$$
x-T x=f
$$

for a given element $f$ of $X$ (Banach space) and described its relation with the properties of Picard iterates, i.e., the sequence $\left\{x_{n}\right\}$ where

$$
x_{n+1}=T x_{n}+f
$$

for an initial value $x_{0}$.

We know that Picard iterates of nonexpansive mappings fail to converge even on a Banach space. Therefore, Mann [2] iterates were introduced to approximate fixed points of nonexpansive mappings. Mann iterates were not adequate for the approximation of fixed points of pseudocontractive mappings and this led to the introduction of Ishikawa iterates [3].

2013 Khan: licensee Springer. This is an Open Access article distributed under the terms of the Creative Commons Attribution License (http://creativecommons.org/licenses/by/2.0), which permits unrestricted use, distribution, and reproduction in any medium, provided the original work is properly cited. 
Let $C$ be a nonempty subset of a metric space $(X, d)$. A mapping $T$ of $C$ into itself is (i) asymptotically nonexpansive if there is a sequence $\left\{k_{n}\right\} \subset[1, \infty)$ with $k_{n} \rightarrow 1$ as $n \rightarrow \infty$ and $d\left(T^{n} x, T^{n} y\right) \leq k_{n} d(x, y)$ for all $x, y \in C$ (when $k_{n}=1$ for each $n \geq 1$, it becomes nonexpansive); (ii) semi-continuous if for any bounded sequence $\left\{x_{n}\right\}$ in $C$ satisfying $d\left(x_{n}, T x_{n}\right) \rightarrow 0$, there exists a subsequence $\left\{x_{n_{i}}\right\}$ of $\left\{x_{n}\right\}$ such that $x_{n_{i}} \rightarrow x \in C$; (iii) completely continuous if every bounded sequence $\left\{x_{n}\right\}$ in $C$ implies that $\left\{T x_{n}\right\}$ has a convergent subsequence.

Nonexpansive mappings (the class of nonlinear mappings containing contractions as a subclass) remain a popular area of research in various fields. The iterative construction of fixed points of these mappings is a fascinating field of research. The fixed point problem for some nonlinear mappings has been studied on linear as well as nonlinear domains [4-8].

Numerous papers have appeared on the iterative construction of fixed points of asymptotically nonexpansive and asymptotically quasi-nonexpansive mappings in uniformly convex Banach spaces [3, 4, 7, 9-18].

The Ishikawa iterative scheme for two asymptotically nonexpansive mappings $S$ and $T$ is defined as

$$
\begin{aligned}
& x_{1}=x \in C, \\
& x_{n+1}=\alpha_{n} T^{n} y_{n}+\left(1-\alpha_{n}\right) x_{n}, \\
& y_{n}=\beta_{n} S^{n} x_{n}+\left(1-\beta_{n}\right) x_{n}, \quad n \geq 1,
\end{aligned}
$$

where $\alpha_{n}, \beta_{n} \in I=[0,1]$.

For $S=T$ in (1.2), we have an Ishikawa type iterative scheme for one mapping [19]

$$
\begin{aligned}
& x_{1}=x \in C, \\
& x_{n+1}=\alpha_{n} T^{n} y_{n}+\left(1-\alpha_{n}\right) x_{n}, \\
& y_{n}=\beta_{n} T^{n} x_{n}+\left(1-\beta_{n}\right) x_{n}, \quad n \geq 1 .
\end{aligned}
$$

When $\beta_{n}=0$ in (1.2), we have the Mann [2] type iterative scheme

$$
\begin{aligned}
& x_{1}=x \in C, \\
& x_{n+1}=\alpha_{n} T^{n} x_{n}+\left(1-\alpha_{n}\right) x_{n}, \quad n \geq 1 .
\end{aligned}
$$

Rhoades [16] established Mann and Ishikawa type convergence results as two separate results as follows.

Theorem 1 ([16], Theorem 2) Let $C$ be a nonempty bounded, closed and convex subset of a uniformly convex Banach space. Let $T$ be a completely continuous asymptotically nonexpansive mapping on $C$ with $k_{n} \geq 1$ satisfying $\sum_{n=1}^{\infty}\left(k_{n}-1\right)<\infty$. Define $\left\{\alpha_{n}\right\}$ to satisfy $\varepsilon \leq \alpha_{n} \leq 1-\varepsilon$ for all $n \geq 1$ and $\varepsilon>0$. Then the Mann type iterative scheme $\left\{x_{n}\right\}$ in (1.4) converges to a fixed point of $T$.

Theorem 2 ([16], Theorem 3) Let C be a nonempty bounded, closed and convex subset of a uniformly convex Banach space. Let $T$ be a completely continuous asymptotically nonexpansive mapping on $C$ with $k_{n} \geq 1$ satisfying $\sum_{n=1}^{\infty}\left(k_{n}-1\right)<\infty$. Define $\left\{\alpha_{n}\right\},\left\{\beta_{n}\right\}$ to satisfy 
$\varepsilon \leq 1-\alpha_{n}, 1-\beta_{n} \leq 1-\varepsilon$ for all $n \geq 1$ and $\varepsilon>0$. Then the Ishikawa type iterative scheme $\left\{x_{n}\right\}$ in (1.3) converges to a fixed point of $T$.

An extension of a linear version (usually in Banach spaces) of a known result to metric fixed point theory has its own importance. As Mann and Ishikawa iterative schemes involve general convex combinations, we need some convex structure in a metric space to investigate their convergence on a nonlinear domain.

Let $(X, d)$ be a metric space. Suppose that there exists a family $\digamma$ of metric segments such that any two points $x, y$ in $X$ are endpoints of a unique metric segment $[x, y] \in \digamma([x, y]$ is an isometric image of the real line interval $[0, d(x, y)])$. We shall denote by $\alpha x \oplus(1-\alpha) y$ the unique point $z$ of $[x, y]$ which satisfies

$$
d(x, z)=(1-\alpha) d(x, y) \quad \text { and } \quad d(z, y)=\alpha d(x, y) \quad \text { for } \alpha \in I .
$$

Such metric spaces are usually called convex metric spaces [20]. One can easily deduce $0 x \oplus 1 y=y, 1 x \oplus 0 y=x$ and $\alpha x \oplus(1-\alpha) x=x$ from the definition of a convex metric space [21-24].

A convex metric space $X$ is hyperbolic if

$$
d(\alpha x \oplus(1-\alpha) y, \alpha z \oplus(1-\alpha) w) \leq \alpha d(x, z)+(1-\alpha) d(y, w)
$$

for all $x, y, z, w \in X$ and $\alpha \in I$ (see also [25]).

For $z=w$, the hyperbolic inequality reduces to convex structure [26]

$$
d(\alpha x \oplus(1-\alpha) y, z) \leq \alpha d(x, z)+(1-\alpha) d(y, z) .
$$

A nonempty subset $C$ of a convex metric space $X$ is convex if $\alpha x \oplus(1-\alpha) y \in C$ for all $x, y \in C$ and $\alpha \in I$.

Normed spaces and their subsets are linear hyperbolic spaces while Hadamard manifolds [27], the Hilbert open unit ball equipped with the hyperbolic metric [28] and the $\operatorname{CAT}(0)$ spaces qualify for the criteria of nonlinear hyperbolic spaces [21, 23, 24, 29].

A convex metric space $X$ is uniformly convex if

$$
\delta(r, \varepsilon)=\inf \left\{1-\frac{1}{r} d\left(a, \frac{1}{2} x \oplus \frac{1}{2} y\right): d(a, x) \leq r, d(a, y) \leq r, d(x, y) \geq r \varepsilon\right\}>0
$$

for any $a \in X, r>0$ and $\varepsilon>0$.

From now onwards we assume that $X$ is a uniformly convex hyperbolic space with the property that for every $s \geq 0, \varepsilon>0$, there exists $\eta(s, \varepsilon)>0$ depending on $s$ and $\varepsilon$ such that $\delta(r, \varepsilon)>\eta(s, \varepsilon)>0$ for any $r>s$.

$\mathrm{Xu}$ [30] extensively used the concept of $p$-uniform convexity (see also [31, p.310]); its nonlinear version for $p=2$ was introduced by Khamsi and Khan [8] as follows:

For a fixed $a \in X, r>0, \varepsilon>0$, define

$$
\Psi(r, \varepsilon)=\inf \left\{\frac{1}{2} d(a, x)^{2}+\frac{1}{2} d(a, y)^{2}-d\left(a, \frac{1}{2} x \oplus \frac{1}{2} y\right)^{2}\right\},
$$


where the infimum is taken over all $x, y \in X$ such that $d(a, x) \leq r, d(a, y) \leq r$ and $d(x, y) \geq r \varepsilon$.

We say that $X$ is 2-uniformly convex if

$$
c_{M}=\inf \left\{\frac{\Psi(r, \varepsilon)}{r^{2} \varepsilon^{2}}: r>0, \varepsilon>0\right\}>0 .
$$

It was shown in [8] that any CAT(0) space is 2-uniformly convex with $c_{M}=\frac{1}{4}$.

Using the concept of a unique point $\alpha x \oplus(1-\alpha) y$ in a metric segment $[x, y]$, we express (1.2)-(1.4) in a convex hyperbolic space as follows:

Ishikawa iterative scheme for two mappings

$$
\begin{aligned}
& x_{1}=x \in C, \\
& x_{n+1}=\alpha_{n} T^{n} y_{n} \oplus\left(1-\alpha_{n}\right) x_{n}, \\
& y_{n}=\beta_{n} S^{n} x_{n} \oplus\left(1-\beta_{n}\right) x_{n}, \quad n \geq 1,
\end{aligned}
$$

where $0 \leq \alpha_{n}, \beta_{n} \leq 1$.

Ishikawa iterative scheme for one mapping

$$
\begin{aligned}
& x_{1}=x \in C, \\
& x_{n+1}=\alpha_{n} T^{n} y_{n} \oplus\left(1-\alpha_{n}\right) x_{n}, \\
& y_{n}=\beta_{n} T^{n} x_{n} \oplus\left(1-\beta_{n}\right) x_{n}, \quad n \geq 1 .
\end{aligned}
$$

Mann iterative scheme

$$
\begin{aligned}
& x_{1}=x \in C, \\
& x_{n+1}=\alpha_{n} T^{n} x_{n} \oplus\left(1-\alpha_{n}\right) x_{n}, \quad n \geq 1 .
\end{aligned}
$$

In the sequel, the following results are needed.

Lemma 1 [7] Suppose that $X$ is a 2-uniformly convex hyperbolic space. Then, for any $\alpha \in$ $(0,1)$, we have that

$$
d(u, \alpha x \oplus(1-\alpha) y)^{2} \leq \alpha d(u, x)^{2}+(1-\alpha) d(u, y)^{2}-4 c_{M} \min \left\{\alpha^{2},(1-\alpha)^{2}\right\} d(x, y)^{2}
$$

for any $u, x, y \in X$.

Lemma 2 [18] Let $\left\{r_{n}\right\},\left\{s_{n}\right\}$ and $\left\{t_{n}\right\}$ be nonnegative real sequences and satisfy

$$
r_{n+1} \leq\left(1+s_{n}\right) r_{n}+t_{n} \quad \text { for all } n \geq 1
$$

If $\sum_{n=1}^{\infty} s_{n}<\infty$ and $\sum_{n=1}^{\infty} t_{n}<\infty$, then $\lim _{n \rightarrow \infty} r_{n}$ exists.

Our purpose in this paper is to approximate a common fixed point of two asymptotically nonexpansive mappings through iterative scheme (1.6) in 2-uniformly convex hyperbolic spaces. This work provides a unified approach to convergence results for Mann and Ishikawa iterative schemes. 


\section{Convergence in 2-uniformly convex hyperbolic spaces}

We set $F(T)=\{x \in X: T x=x\}$ and $F=F(S) \cap F(T) \neq \emptyset$.

Lemma 3 Let $C$ be a nonempty convex subset of a hyperbolic space $X$, and let $S, T: C \rightarrow C$ be asymptotically nonexpansive mappings with sequence $\left\{k_{n}\right\} \subset[1, \infty)$ such that $\sum_{n=1}^{\infty}\left(k_{n}-\right.$ $1)<\infty$. Then, for the sequence $\left\{x_{n}\right\}$ in (1.6), $\lim _{n \rightarrow \infty} d\left(x_{n}, p\right)$ exists for all $p \in F$.

Proof Let $p \in F$. By (1.5) and (1.6), we have

$$
\begin{aligned}
d\left(x_{n+1}, p\right) & =d\left(\alpha_{n} T^{n} y_{n} \oplus\left(1-\alpha_{n}\right) x_{n}, p\right) \\
& \leq \alpha_{n} d\left(T^{n} y_{n}, p\right)+\left(1-\alpha_{n}\right) d\left(x_{n}, p\right) \\
& \leq \alpha_{n} k_{n} d\left(y_{n}, p\right)+\left(1-\alpha_{n}\right) d\left(x_{n}, p\right) \\
& =\alpha_{n} k_{n} d\left(\beta_{n} S^{n} x_{n} \oplus\left(1-\beta_{n}\right) x_{n}, p\right)+\left(1-\alpha_{n}\right) d\left(x_{n}, p\right) \\
& \leq \alpha_{n} k_{n}\left[\beta_{n} d\left(S^{n} x_{n}, p\right)+\left(1-\beta_{n}\right) d\left(x_{n}, p\right)\right]+\left(1-\alpha_{n}\right) d\left(x_{n}, p\right) \\
& \leq \alpha_{n} \beta_{n} k_{n}^{2} d\left(x_{n}, p\right)+\alpha_{n}\left(1-\beta_{n}\right) k_{n} d\left(x_{n}, p\right)+\left(1-\alpha_{n}\right) d\left(x_{n}, p\right) \\
& \leq \alpha_{n} \beta_{n} k_{n}^{2} d\left(x_{n}, p\right)+\alpha_{n}\left(1-\beta_{n}\right) k_{n}^{2} d\left(x_{n}, p\right)+\left(1-\alpha_{n}\right) k_{n}^{2} d\left(x_{n}, p\right) \\
& =k_{n}^{2} d\left(x_{n}, p\right) .
\end{aligned}
$$

That is,

$$
d\left(x_{n+1}, p\right) \leq k_{n}^{2} d\left(x_{n}, p\right)
$$

Since $\left\{k_{n}\right\}$ is bounded, therefore

$$
d\left(x_{n+1}, p\right) \leq\left[1+M\left(k_{n}-1\right)\right] d\left(x_{n}, p\right)
$$

where $M=\sup _{n \geq 1}\left(k_{n}+1\right)$. As $M \sum_{n=1}^{\infty}\left(k_{n}-1\right)<\infty$, so by Lemma $2, \lim _{n \rightarrow \infty} d\left(x_{n}, p\right)$ exists.

Lemma 4 Let $C$ be a nonempty convex subset of a hyperbolic space $X$, and let $S, T: C \rightarrow C$ be asymptotically nonexpansive mappings with sequence $\left\{k_{n}\right\} \subset[1, \infty)$ such that $\sum_{n=1}^{\infty}\left(k_{n}-\right.$ $1)<\infty$. Then, for the sequence $\left\{x_{n}\right\}$ in (1.6), we have that

$$
d\left(x_{n}, p\right) \leq s d\left(x_{n_{0}}, p\right)
$$

for all $n>n_{0} \geq 2, p \in F$ and some $s>0$.

Proof With the help of inequality $x \leq e^{x-1}$ for $x \geq 1$ and (2.1), we have

$$
\begin{aligned}
d\left(x_{n}, p\right) & \leq k_{n-1}^{2} d\left(x_{n-1}, p\right) \\
& \leq e^{2\left(k_{n-1}-1\right)} d\left(x_{n-1}, p\right) \\
& \leq \cdots \\
& \leq \cdots
\end{aligned}
$$




$$
\begin{aligned}
& \leq e^{2 \sum_{j=n_{0}}^{n-1}\left(k_{j}-1\right)} d\left(x_{n_{0}}, p\right) \\
& \leq e^{2 \sum_{j=1}^{\infty}\left(k_{j}-1\right)} d\left(x_{n_{0}}, p\right) \\
& =s d\left(x_{n_{0}}, p\right) \quad \text { where } s=e^{2 \sum_{j=1}^{\infty}\left(k_{j}-1\right)} .
\end{aligned}
$$

Theorem 3 Let $C$ be a nonempty closed and convex subset of a complete hyperbolic space $X$, and let $S, T: C \rightarrow C$ be asymptotically nonexpansive mappings with sequence $\left\{k_{n}\right\} \subset$ $[1, \infty)$ such that $\sum_{n=1}^{\infty}\left(k_{n}-1\right)<\infty$. Then $\left\{x_{n}\right\}$ in $(1.6)$ converges to a point in $F$ if and only if $\liminf _{n \rightarrow \infty} d\left(x_{n}, F\right)=0$, where $d(x, F)=\inf \{d(x, p): p \in F\}$.

Proof We only prove sufficiency. Suppose that $\liminf _{n \rightarrow \infty} d\left(x_{n}, F\right)=0$. It has been shown in the proof of Lemma 3 that $d\left(x_{n+1}, p\right) \leq k_{n}^{2} d\left(x_{n}, p\right)$. By the properties of inf, we have that $d\left(x_{n+1}, F\right) \leq k_{n}^{2} d\left(x_{n}, F\right)$ and hence, by Lemma $2, \lim _{n \rightarrow \infty} d\left(x_{n}, F\right)$ exists. Therefore the hypothesis $\liminf _{n \rightarrow \infty} d\left(x_{n}, F\right)=0$ gives that $\lim _{n \rightarrow \infty} d\left(x_{n}, F\right)=0$. Next we show that $\left\{x_{n}\right\}$ is a Cauchy sequence. Let $\varepsilon>0$. Since $\lim _{n \rightarrow \infty} d\left(x_{n}, F\right)=0$, there exists $n_{0} \geq 1$ such that $d\left(x_{n_{0}}, F\right)<\frac{\varepsilon}{3 s}$. Hence there must exist $q \in F$ such that $d\left(x_{n_{0}}, q\right)<\frac{\varepsilon}{2 s}$.

Now, for any $n>m \geq n_{0}$, we have from the estimate in the proof of Lemma 4

$$
\begin{aligned}
d\left(x_{n+m}, x_{n}\right) & \leq d\left(x_{n+m}, p\right)+d\left(x_{n}, p\right) \\
& \leq 2 s d\left(x_{n_{0}}, p\right)<\varepsilon .
\end{aligned}
$$

This proves that $\left\{x_{n}\right\}$ is a Cauchy sequence. Since $X$ is complete and $C$ is its closed subset, therefore $\lim _{n \rightarrow \infty} x_{n}=q \in C$. Now $\lim _{n \rightarrow \infty} d\left(x_{n}, F\right)=0$ gives that $d(q, F)=0$. As $F$ is closed, so $q \in F$.

Lemma 5 Let $C$ be a nonempty convex subset of a 2-uniformly convex hyperbolic space $X$, and let $S, T: C \rightarrow C$ be asymptotically nonexpansive mappings with sequence $\left\{k_{n}\right\} \subset[1, \infty)$ such that $\sum_{n=1}^{\infty}\left(k_{n}-1\right)<\infty$. Define $\left\{\alpha_{n}\right\}$ and $\left\{\beta_{n}\right\}$ to satisfy $0<\varepsilon \leq \alpha_{n}, \beta_{n} \leq 1-\varepsilon$ for all $n \geq 1$. Then, for the sequence $\left\{x_{n}\right\}$ in (1.6), $\lim _{n \rightarrow \infty} d\left(S x_{n}, x_{n}\right)=0=\lim _{n \rightarrow \infty} d\left(T x_{n}, x_{n}\right)$.

Proof Let $p \in F$. Then, by Lemma 1, we have

$$
\begin{aligned}
d\left(x_{n+1}, p\right)^{2}= & d\left(\alpha_{n} T^{n} y_{n} \oplus\left(1-\alpha_{n}\right) x_{n}, p\right)^{2} \\
\leq & \alpha_{n} d\left(T^{n} y_{n}, p\right)^{2}+\left(1-\alpha_{n}\right) d\left(x_{n}, p\right)^{2} \\
& -4 c_{M} \min \left\{\alpha_{n}^{2},\left(1-\alpha_{n}\right)^{2}\right\} d\left(T^{n} y_{n}, x_{n}\right)^{2} \\
\leq & \alpha_{n} d\left(T^{n} y_{n}, p\right)^{2}+\left(1-\alpha_{n}\right) d\left(x_{n}, p\right)^{2} \\
& -4 c_{M} \alpha_{n}^{2}\left(1-\alpha_{n}\right)^{2} d\left(T^{n} y_{n}, x_{n}\right)^{2} \\
\leq & \alpha_{n} k_{n}^{2} d\left(y_{n}, p\right)^{2}+\left(1-\alpha_{n}\right) d\left(x_{n}, p\right)^{2} \\
& -4 c_{M} \varepsilon^{4} d\left(T^{n} y_{n}, x_{n}\right)^{2} \\
= & \alpha_{n} k_{n}^{2} d\left(\beta_{n} S^{n} x_{n} \oplus\left(1-\beta_{n}\right) x_{n}, p\right)^{2} \\
& +\left(1-\alpha_{n}\right) d\left(x_{n}, p\right)^{2} \\
& -4 c_{M} \alpha^{2}(1-\alpha)^{2} d\left(T^{n} y_{n}, x_{n}\right)^{2}
\end{aligned}
$$




$$
\begin{aligned}
\leq & \alpha_{n} k_{n}^{2} \beta_{n} d\left(S^{n} x_{n}, p\right)^{2}+\alpha_{n} k_{n}^{2}\left(1-\beta_{n}\right) d\left(x_{n}, p\right)^{2} \\
& -4 c_{M} \alpha_{n} k_{n}^{2} \min \left\{\beta_{n}^{2},\left(1-\beta_{n}\right)^{2}\right\} d\left(T^{n} y_{n}, x_{n}\right)^{2} \\
& +\left(1-\alpha_{n}\right) d\left(x_{n}, p\right)^{2}-4 c_{M} \varepsilon^{4} d\left(T^{n} y_{n}, x_{n}\right) \\
\leq & \alpha_{n} \beta_{n} k_{n}^{4} d\left(x_{n}, p\right)^{2}+\alpha_{n}\left(1-\beta_{n}\right) k_{n}^{2} d\left(x_{n}, p\right)^{2} \\
& +\left(1-\alpha_{n}\right) d\left(x_{n}, p\right)^{2} \\
& -4 c_{M} k_{n}^{2} \varepsilon^{5} d\left(T^{n} x_{n}, x_{n}\right)-4 c_{M} \varepsilon^{4} d\left(T^{n} y_{n}, x_{n}\right) \\
\leq & \alpha_{n} \beta_{n} k_{n}^{4} d\left(x_{n}, p\right)^{2}+\alpha_{n}\left(1-\beta_{n}\right) k_{n}^{4} d\left(x_{n}, p\right)^{2} \\
& +\left(1-\alpha_{n}\right) k_{n}^{4} d\left(x_{n}, p\right)^{2} \\
& -4 c_{M} k_{n}^{2} \varepsilon^{3} d\left(T^{n} x_{n}, x_{n}\right)-4 c_{M} \varepsilon^{2} d\left(T^{n} y_{n}, x_{n}\right) \\
= & k_{n}^{4} d\left(x_{n}, p\right)^{2}-4 c_{M} k_{n}^{2} \varepsilon^{5} d\left(S^{n} x_{n}, x_{n}\right)-4 c_{M} \varepsilon^{4} d\left(T^{n} y_{n}, x_{n}\right) \\
= & d\left(x_{n}, p\right)^{2}+\left(k_{n}^{4}-1\right) d\left(x_{n}, p\right)^{2}-4 c_{M} k_{n}^{2} \varepsilon^{5} d\left(S^{n} x_{n}, x_{n}\right) \\
& -4 c_{M} \varepsilon^{4} d\left(T^{n} y_{n}, x_{n}\right) .
\end{aligned}
$$

Since $\lim _{n \rightarrow \infty} d\left(x_{n}, p\right)$ exists, therefore we have

$$
d\left(x_{n+1}, p\right)^{2} \leq d\left(x_{n}, p\right)^{2}-4 c_{M} \varepsilon^{3} d\left(T^{n} x_{n}, x_{n}\right)-4 c_{M} \varepsilon^{2} d\left(T^{n} y_{n}, x_{n}\right)+\left(k_{n}^{4}-1\right) M
$$

for some $M>0$.

This inequality implies the following two important inequalities:

$$
4 c_{M} \varepsilon^{4} d\left(T^{n} y_{n}, x_{n}\right) \leq d\left(x_{n}, p\right)^{2}-d\left(x_{n+1}, p\right)^{2}+\left(k_{n}^{4}-1\right) M
$$

and

$$
4 c_{M} \varepsilon^{5} d\left(S^{n} x_{n}, x_{n}\right) \leq d\left(x_{n}, p\right)^{2}-d\left(x_{n+1}, p\right)^{2}+\left(k_{n}^{4}-1\right) M
$$

Let $m$ be any positive integer. Summing up the terms from 1 to $m$ on both sides in inequality (2.2), we have

$$
\begin{aligned}
4 c_{M} \varepsilon^{4} \sum_{n=1}^{m} d\left(T^{n} y_{n}, x_{n}\right) & \leq d\left(x_{1}, p\right)^{2}-d\left(x_{m+1}, p\right)^{2}+\sum_{n=1}^{m}\left(k_{n}^{4}-1\right) M \\
& \leq d\left(x_{1}, p\right)^{2}+\sum_{n=1}^{m}\left(k_{n}^{4}-1\right) M .
\end{aligned}
$$

When $m \rightarrow \infty$ in the above inequality, we get that

$$
4 c_{M} \varepsilon^{4} \sum_{n=1}^{\infty} d\left(T^{n} y_{n}, x_{n}\right)<\infty
$$

and hence

$$
\lim _{n \rightarrow \infty} d\left(T^{n} y_{n}, x_{n}\right)=0
$$


Adapting a similar procedure for inequality (2.3), we get that

$$
\lim _{n \rightarrow \infty} d\left(S^{n} x_{n}, x_{n}\right)=0 .
$$

Therefore the inequality

$$
\begin{aligned}
d\left(T^{n} x_{n}, x_{n}\right) & \leq d\left(T^{n} x_{n}, T^{n} y_{n}\right)+d\left(T^{n} y_{n}, x_{n}\right) \\
& \leq k_{n} d\left(x_{n}, y_{n}\right)+d\left(T^{n} y_{n}, x_{n}\right) \\
& =k_{n} d\left(x_{n}, \beta_{n} S^{n} x_{n} \oplus\left(1-\beta_{n}\right) x_{n}\right)+d\left(T^{n} y_{n}, x_{n}\right) \\
& =k_{n} \beta_{n} d\left(x_{n}, S^{n} x_{n}\right)+d\left(T^{n} y_{n}, x_{n}\right) \\
& \leq k_{n} d\left(x_{n}, S^{n} x_{n}\right)+d\left(T^{n} y_{n}, x_{n}\right)
\end{aligned}
$$

together with (2.4) and (2.5) gives that

$$
\lim _{n \rightarrow \infty} d\left(T^{n} x_{n}, x_{n}\right)=0
$$

Next we prove that

$$
\lim _{n \rightarrow \infty} d\left(S x_{n}, x_{n}\right)=0=\lim _{n \rightarrow \infty} d\left(T x_{n}, x_{n}\right) .
$$

Note that

$$
\begin{aligned}
d\left(x_{n+1}, x_{n}\right) & =d\left(\alpha_{n} T^{n} y_{n} \oplus\left(1-\alpha_{n}\right) x_{n}, x_{n}\right) \\
& =\alpha_{n} d\left(T^{n} y_{n}, x_{n}\right) \\
& \leq(1-\varepsilon) d\left(T^{n} y_{n}, x_{n}\right) \rightarrow 0 \quad \text { as } n \rightarrow \infty .
\end{aligned}
$$

Finally,

$$
\begin{aligned}
d\left(x_{n+1}, S x_{n+1}\right) & \leq d\left(x_{n+1}, S^{n+1} x_{n+1}\right)+d\left(S x_{n+1}, S^{n+1} x_{n+1}\right) \\
& \leq d\left(x_{n+1}, S^{n+1} x_{n+1}\right)+k_{1} d\left(x_{n+1}, S^{n} x_{n+1}\right) \\
& \leq k_{1}\left[d\left(x_{n+1}, x_{n}\right)+d\left(x_{n}, S^{n} x_{n}\right)+d\left(S^{n} x_{n}, S^{n} x_{n+1}\right)\right]+d\left(x_{n+1}, S^{n+1} x_{n+1}\right) \\
& \leq d\left(x_{n+1}, S^{n+1} x_{n+1}\right)+k_{1} d\left(x_{n}, S^{n} x_{n}\right)+k_{1}\left(1+k_{n}\right) d\left(x_{n+1}, x_{n}\right)
\end{aligned}
$$

gives that

$$
\lim _{n \rightarrow \infty} d\left(S x_{n}, x_{n}\right)=0 .
$$

Similarly,

$$
\lim _{n \rightarrow \infty} d\left(T x_{n}, x_{n}\right)=0 .
$$

That is,

$$
\lim _{n \rightarrow \infty} d\left(S x_{n}, x_{n}\right)=0=\lim _{n \rightarrow \infty} d\left(T x_{n}, x_{n}\right) .
$$


The following concept is needed to proceed further.

Let $f$ be nondecreasing on $[0, \infty)$ with $f(0)=0$ and $f(t)>0$ for all $t \in(0, \infty)$. Then the mappings $S, T: C \rightarrow C$ with $F \neq \emptyset$ satisfy Condition (A) if

$$
d(x, T x) \geq f(d(x, F)) \quad \text { or } \quad d(x, S x) \geq f(d(x, F)) \quad \text { for } x \in C .
$$

Using Condition (A) and Theorem 3, we prove a convergence theorem in complete 2uniformly convex spaces as follows.

Theorem 4 Let $C$ be a nonempty convex subset of a complete 2-uniformly convex hyperbolic space $X$. Let $S, T: C \rightarrow C$ be asymptotically nonexpansive mappings with sequence $\left\{k_{n}\right\} \subset[1, \infty)$ such that $\sum_{n=1}^{\infty}\left(k_{n}-1\right)<\infty$ and satisfy Condition (A). Define $\left\{\alpha_{n}\right\}$ and $\left\{\beta_{n}\right\}$ to satisfy $0<\varepsilon \leq \alpha_{n}, \beta_{n} \leq 1-\varepsilon$ for $n \geq 1$. Then the sequence $\left\{x_{n}\right\}$ in (1.6) converges to a point in $F$.

Proof By Lemma 5, $\lim _{n \rightarrow \infty} d\left(S x_{n}, x_{n}\right)=0=\lim _{n \rightarrow \infty} d\left(T x_{n}, x_{n}\right)$. Using Condition (A), we get that $\lim _{n \rightarrow \infty} d\left(x_{n}, F\right)=0$. Now Theorem 3 gives that $\left\{x_{n}\right\}$ converges to a point in $F$.

Another convergence theorem is established in the following result under any of Conditions (ii)-(iii) without requiring the completeness of the space $X$.

Theorem 5 Let $C$ be a nonempty convex subset of a 2-uniformly convex hyperbolic space $X$. Let $S, T: C \rightarrow C$ be asymptotically nonexpansive mappings with sequence $\left\{k_{n}\right\} \subset[1, \infty)$ such that $\sum_{n=1}^{\infty}\left(k_{n}-1\right)<\infty$ and either $S$ or $T$ is semi-compact. Define $\left\{\alpha_{n}\right\}$ and $\left\{\beta_{n}\right\}$ to satisfy $0<\varepsilon \leq \alpha_{n}, \beta_{n} \leq 1-\varepsilon$ for all $n \geq 1$. Then the sequence $\left\{x_{n}\right\}$ in (1.6) converges to a point in $F$.

Proof Lemma 5 gives that $\lim _{n \rightarrow \infty} d\left(S x_{n}, x_{n}\right)=0=\lim _{n \rightarrow \infty} d\left(T x_{n}, x_{n}\right)$. Suppose that $T$ is semi-compact. Since $\lim _{n \rightarrow \infty} d\left(x_{n}, p\right)$ exists, therefore $\left\{x_{n}\right\}$ is bounded. As $\lim _{n \rightarrow \infty} d\left(T x_{n}\right.$, $\left.x_{n}\right)=0$ and $T$ is semi-compact, so there is a subsequence $\left\{x_{n_{i}}\right\}$ of $\left\{x_{n}\right\}$ such that $x_{n_{i}} \rightarrow q \in C$, and hence $T x_{n_{i}} \rightarrow T q$ and $S x_{n_{i}} \rightarrow S q$. Therefore $\lim _{i \rightarrow \infty} d\left(S x_{n_{i}}, x_{n_{i}}\right)=0=$ $\lim _{i \rightarrow \infty} d\left(T x_{n_{i}}, x_{n_{i}}\right)$ implies that $d(S q, q)=0=d(T q, q)$. That is, $q \in F$. As $\lim _{n \rightarrow \infty} d\left(x_{n}, p\right)$ exists and $x_{n_{i}} \rightarrow q$, therefore $x_{n} \rightarrow q$.

Let $\left\{T_{i}: i=1,2, \ldots, k\right\}$ be a family of mappings on $C$. The multi-step iteration scheme of Khan et al. [12] may be adapted in a convex hyperbolic space as follows:

$$
\begin{aligned}
& x_{n+1}=\left(1-\alpha_{k n}\right) x_{n} \oplus \alpha_{k n} T_{k}^{n} y_{(k-1) n}, \\
& y_{(k-1) n}=\left(1-\alpha_{(k-1) n}\right) x_{n} \oplus \alpha_{(k-1) n} T_{k-1}^{n} y_{(k-2) n}, \\
& y_{(k-2) n}=\left(1-\alpha_{(k-2) n}\right) x_{n} \oplus \alpha_{(k-2) n} T_{k-2}^{n} y_{(k-3) n}, \\
& \ldots \\
& y_{2 n}=\left(1-\alpha_{2 n}\right) x_{n} \oplus \alpha_{2 n} T_{2}^{n} y_{1 n}, \\
& y_{1 n}=\left(1-\alpha_{1 n}\right) x_{n} \oplus \alpha_{1 n} T_{1}^{n} y_{0 n},
\end{aligned}
$$

where $y_{0 n}=x_{n}$ for all $n \geq 1$. 
Following the line of action of the proofs of Theorem 3 and Lemma 5, we can easily prove the following results.

Theorem 6 Let $C$ be a nonempty closed and convex subset of a complete 2-uniformly convex hyperbolic space $X$, and let $\left\{T_{i}: i=1,2, \ldots, k\right\}$ be a family of asymptotically quasinonexpansive self-mappings of $C$, i.e., $d\left(T_{i}^{n} x, p_{i}\right) \leq u_{\text {in }} d\left(x, p_{i}\right)$ for all $x \in C$ and $p_{i} \in F\left(T_{i}\right)$, $i=1,2, \ldots, k$. Suppose that $F_{1}=\bigcap_{i=1}^{k} F\left(T_{i}\right) \neq \emptyset, x_{1} \in C$ and $\sum_{n=1}^{\infty}\left(u_{i n}-1\right)<\infty$ for all $i$. Then the iterative sequence $\left\{x_{n}\right\}$, defined by (2.6), converges to a common fixed point of the family of mappings if and only if $\liminf _{n \rightarrow \infty} d\left(x_{n}, F_{1}\right)=0$.

Theorem 7 Let $C$ be a nonempty closed and convex subset of a 2-uniformly convex hyperbolic space $X$, and let $\left\{T_{i}: i=1,2,3, \ldots, k\right\}$ be a family of asymptotically nonexpansive mappings of $C$, i.e., $d\left(T_{i}^{n} x, p_{i}\right) \leq u_{\text {in }} d\left(x, p_{i}\right)$ for all $x \in C$ and $p_{i} \in F\left(T_{i}\right)$, where $\left\{u_{\text {in }}\right\}$ are sequences in $[1, \infty)$ with $\sum_{n=1}^{\infty}\left(u_{i n}-1\right)<\infty$ for each $i \in\{1,2,3, \ldots, k\}$. Assume that $F_{1} \neq \emptyset$ and the sequence $\left\{x_{n}\right\}$ is in (2.6) with $\alpha_{i n} \in[\delta, 1-\delta]$ for some $\delta \in\left(0, \frac{1}{2}\right)$. If for some $i, 1 \leq i \leq k$, $T_{i}$ is semi-compact, then $\left\{x_{n}\right\}$ converges to a point in $F_{1}$.

Remark 1 (1) Theorem 5 extends (unifies) Theorem 2 of Khan and Takahashi [14] (Theorems 1-2) in the setting of 2-uniformly convex hyperbolic spaces.

(2) Theorem 6 establishes Theorem 1 by Qihou [15] together with its Corollaries 1 and 2, which are themselves extensions of the results of Ghosh and Debnath [11] and Petryshyn and Williamson [32], for two asymptotically nonexpansive mappings on a 2-uniformly convex hyperbolic space.

(3) All the results of this paper, in particular, hold in CAT(0) spaces.

Remark 2 In a uniformly convex Banach space $B$, iterative scheme (2.6) for nonexpansive mappings becomes the scheme $(*)$ of Kuhfittig ([29], p.137) which he applied to solve the system of equations of the type

$$
x-S_{i} x=f_{i} \quad \text { for } i=1,2,3, \ldots, m,
$$

where each $S_{i}$ is a nonexpansive self-mapping on $X$ and each $f_{i}$ is a given element of $X$. Following Kuhfittig [29], we can apply our iteration scheme (2.6) to find a solution of the system of equations of the type

$$
x-S_{i}^{n} x=f_{i} \quad \text { for } i=1,2,3, \ldots, m
$$

for a family $\left\{S_{i}\right\}$ of asymptotically nonexpansive mappings on $B$.

Competing interests

The author declares that he has no competing interests. 


\section{References}

1. Browder, FE, Petryshyn, WV: The solution by iteration of nonlinear functional equations in Banach spaces. Bull. Am. Math. Soc. 72, 571-575 (1966)

2. Mann, WR: Mean value methods in iteration. Proc. Am. Math. Soc. 4, 506-510 (1953)

3. Ishikawa, S: Fixed point by a new iteration method. Proc. Am. Math. Soc. 44, 147-150 (1974)

4. Fukhar-ud-din, H, Khan, AR, Akhtar, Z: Fixed point results for generalized nonexpansive maps in uniformly convex metric spaces. Nonlinear Anal. 75, 4747-4760 (2012)

5. Goebel, K, Kirk, W: A fixed point theorem for asymptotically nonexpansive mappings. Proc. Am. Math. Soc. 35 171-174 (1972)

6. Ibn Dehaish, BA: Ishikawa iteration process for asymptotic pointwise nonexpansive mappings in metric spaces. Fixed Point Theory Appl. 2013, Article ID 98 (2013). doi:10.1186/1687-1812-2013-98

7. Ibn Dehaish, BA, Khamsi, MA, Khan, AR: Mann iteration process for asymptotic pointwise nonexpansive mappings in metric spaces. J. Math. Anal. Appl. 397, 861-868 (2013)

8. Khamsi, MA, Khan, AR: Inequalities in metric spaces with applications. Nonlinear Anal. 74, 4036-4045 (2011)

9. Fukhar-ud-din, $\mathrm{H}$, Khan, SH: Convergence of iterates with errors of asymptotically quasi-nonexpansive mappings and applications. J. Math. Anal. Appl. 328, 821-829 (2007)

10. Fukhar-ud-din, H, Khan, AR, Kalsoom, A, Khan, MAA: One-step implicit algorithm for two finite families of nonexpansive maps in hyperbolic spaces. J. Adv. Math. Stud. 6(1), 73-81 (2013)

11. Ghosh, MK, Debnath, L: Convergence of Ishikawa iterates of quasi-nonexpansive mappings. J. Math. Anal. Appl. 207, 96-103 (1997)

12. Khan, AR, Domlo, AA, Fukhar-ud-din, H: Common fixed points Noor iteration for a finite family of asymptotically quasi-nonexpansive mappings in Banach spaces. J. Math. Anal. Appl. 341, 1-11 (2008)

13. Khan, SH, Fukhar-ud-din, H: Weak and strong convergence of a scheme with errors for two nonexpansive mappings. Nonlinear Anal. 61, 1295-1301 (2005)

14. Khan, SH, Takahashi, W: Approximating common fixed points of two asymptotically nonexpansive mappings. Sci. Math. Jpn. 53, 143-148 (2001)

15. Qihou, L: Iterative sequences for asymptotically quasi-nonexpansive mappings. J. Math. Anal. Appl. 259, 1-7 (2001)

16. Rhoades, BE: Fixed point iterations for certain nonlinear mappings. J. Math. Anal. Appl. 183, 118-120 (1994)

17. Schu, J: Weak and strong convergence of fixed points of asymptotically nonexpansive mappings. Bull. Aust. Math. Soc. 43, 153-159 (1991)

18. Tan, KK, Xu, HK: Fixed point iteration process for asymptotically nonexpansive mappings. Proc. Am. Math. Soc. 122, 733-739 (1994)

19. Khan, AR: On modified Noor iterations for asymptotically nonexpansive mappings. Bull. Belg. Math. Soc. Simon Stevin $17,127-140(2010)$

20. Menger, K: Untersuchungen über allgemeine Metrik. Math. Ann. 100, 75-163 (1928)

21. Kirk, WA: Geodesic geometry and fixed point theory. II. In: International Conference on Fixed Point Theory and Applications, pp. 113-142. Yokohama Publ., Yokohama (2004)

22. Kirk, WA: A fixed point theorem in CAT(0) spaces and R-trees. Fixed Point Theory Appl. 4, 309-316 (2004)

23. Kirk, WA: Fixed Point Theory for Nonexpansive Mappings, I and II. Lecture Notes in Mathematics, vol. 886, pp. 485-505. Springer, Berlin (1981)

24. Leustean, L: A quadratic rate of asymptotic regularity for CAT(0)-spaces. J. Math. Anal. Appl. 325, 386-399 (2007)

25. Abbas, M, Khamsi, MA, Khan, AR: Common fixed point and invariant approximation in hyperbolic ordered metric spaces. Fixed Point Theory Appl. 2011, Article ID 25 (2011). doi:10.1186/1687-1812-2011-25

26. Takahashi, W: A convexity in metric spaces and nonexpansive mappings. Kodai Math. Semin. Rep. 22, 142-149 (1970)

27. Busemann, H: Spaces with non-positive curvature. Acta Math. 80, 259-310 (1948)

28. Goebel, K, Reich, S: Uniform Convexity, Hyperbolic Geometry, and Nonexpansive Mappings. Series of Monographs and Textbooks in Pure and Applied Mathematics, vol. 83. Dekker, New York (1984)

29. Kuhfittig, PKF: Common fixed points of nonexpansive mappings by iteration. Pac. J. Math. 97, 137-139 (1981)

30. Xu, HK: Inequalities in Banach spaces with applications. Nonlinear Anal. 16, 1127-1138 (1991)

31. Beauzamy, B: Introduction to Banach Spaces and Their Geometry. North-Holland, Amsterdam (1985)

32. Petryshyn, WV, Williamson, TE: Strong and weak convergence of the sequence of successive approximations for quasi-nonexpansive mappings. J. Math. Anal. Appl. 43, 459-497 (1973)

10.1186/1687-1812-2013-290

Cite this article as: Khan: Common fixed point and solution of nonlinear functional equations. Fixed Point Theory and Applications 2013, 2013:290 